\title{
Öğretmen Adaylarının Mobil Öğrenmeye İlişkin Tutumlar1
}

\author{
DOI: $10.26466 /$ opus.595870
}

*

\author{
Kemal Turgut* - Elif Akdemir** \\ *YL Öğr. Zonguldak Bülent Ecevit Üniversitesi, Sosyal Bil. Enstitüsü Zonguldak/ Türkiye \\ E-Posta: kemalturgut@yahoo.com \\ ORCID: 0000-0002-0003-7378 \\ ${ }^{* *}$ Dr. Öğr. Üyesi Zonguldak Bülent Ecevit Üniversitesi, Eğitim Fakültesi, Zonguldak/ Türkiye \\ E-Posta: akdemirelif@gmail.com \\ ORCID: $\underline{0000-0002-1225-3393}$
}

\section{Öz}

Nitelikli bilgiye ulaşmak eăitim öğretimin verimliliğinde önemli yer tutmaktadır. Bireyin öğrenmesini desteklemek amacı ile bilgi aktarım araçlarında son yıllarda değişimlerin yaşandığı gözlemlenmektedir. Özellikle akull cep telefonlar ve tabletler ile hayatımıza giren yeni bilgi aktarım vasıtalarımın eğitim öğretim ortamında bilgi aktarımı amacı ile kullanılmasında, öğretmen adaylarının bu yeni ö̆renmeye ilişkin tutumlarının belirlenmesi önem kazanmaktadır. Bu çalışmada öğretmen adaylarının mobil öğrenmeye ilişkin tutumlarımın belirlenmesi hedeflenmiştir. Çalışmada araştırma amacına ulaşmak için nicel araştırmalardan biri olan tarama yöntemlerinden tek zamanlı verilerin toplandığı kesitsel anket çalışma deseni (Cross-Sectional Survey Design) kullanılmıştır. Çalışmaya ilişkin verilerin toplanmasında M-öğrenme tutum ölçeği kullanılmıştır. Çalışma verileri bir devlet üniversitesinin eğitim fakültesinin Sinıf, Sosyal Bilgiler, Okul Öncesi, İlköğretim Matematik, Türkçe Ve Zihinsel Engelliler Öğretmenliği bölümlerinde öğrenim gören 1004 öğretmen adayindan elde edilmiştir. Çalışmaya katılanların büyük bir çoğunluğunu kadın öğretmen adayları oluşturmuştur. Çalışma sonuçları öğretmen adaylarının mobil öğrenmeye ilişkin tutumlarının pozitif olduğunu göstermiştir. Bu sonuçlara dayanarak gelecekte ilköğretim ve ortaöğretim için planlanacak eğitim öğretim etkinliklerinde mobil öğrenme araçlarına yer verilebileceği anlaşılmaktadır.

Anahtar Kelimeler: Ĕ̈itim programı, mobil öğrenme, öğretmen adayları, tutum 


\title{
The Attitude of Prospective Teachers Towards Mobile Learning
}

*

\begin{abstract}
Accessing qualified information has an important place in the efficiency of education and training. In order to support the learning that takes place in the individual, there are changes in the means of information transferred from the outside. It is important to determine the attitudes of prospective teachers towards the new learning environment which is used to transfer information in education through devices such as smart phones and tablets. The purpose of this study is to investigate the attitudes of prospective teachers towards mobile learning. Being one of the quantitative research, the Cross-Sectional Survey design was used in the study. Data in the study were collected using the M-learning attitude scale. The data for the study were obtained on a volunteer basis from students in six different departments attending the education faculty of a state university. The results of the study showed that prospective teachers' attitudes towards mobile learning were positive. Based on these results, it is understood that mobile learning tools may be included in the educational activities to be planned for primary and secondary education in the future.
\end{abstract}

Keywords: Curriculum, mobile learning, prospective teachers, attitude 


\section{Giriş}

Eğitim öğretim amacı ile geçmişten günümüze farklı teknolojiler kullanılmıştır. Günümüz toplumlarında mobil cihazların kullanımının arttı̆̆1 gözlemlenmektedir (Briz-Ponce, Pereira, Carvalho, Juanes-Méndez, ve García-Peñalvo, 2017). Eğitim amaçlı kullanılabilecek mobil cihazlar günümüzde yaygın olarak hemen hemen her bireyin kullandığı akıllı telefonlardan tablet bilgisayarlara kadar değişen yelpazeyi kapsamaktadır. Mobil cihazların başlıca kullanım amacı iletişim, eğlence ve bilgiye erişimdir. Mobil cihazların öğretim amaçlı kullanılabilme potansiyeli öğrencilere okul içinde ve okul dışında da erişim için önemlidir. Mobil öğrenme, mobil araçlardan PDA, mobil telefon, iPod v.b. cihazların öğrenme amacı ile kullanımı olarak ifade edilmektedir (Sharples, Arnedillo-Sánchez, Milrad, ve Vavoula, 2009). Mobil cihazlar aracılı̆̆ ile öğrenme, öğrencilere okul içinde ve dışında işbirliği yapma ve birbirleri arasında fikir paylaşımı yapmaya olanak sağlamaktadır (Al-Emran, Elsherif ve Shaalan, 2016).

Öğretmenlerin bilgi ve iletişim teknolojilerine olan tutumları bu teknolojilerin eğitimde yaygınlaşması için önemlidir. Sánchez, Marcos ve GuanLin (2012) çalışmalarında sınıfta kullanılan bilgi iletişim teknolojilerine ilişkin hizmet içi eğitim kursuna katılan öğretmenlerin bu teknolojilere ilişkin tutumlarını belirlemeyi hedeflemişlerdir. Bu eğitimde işletim sistemleri, etkileşimli dijital tahtalar, tablet bilgisayarlar ve çoklu ortam tasarımı, öğretim stratejilerine yönelik bilgiler verilmiştir. Hizmetiçi eğitime katılan 157 öğretmenin katıldığı çalışma sonuçları hizmetiçi eğitime katılan öğretmenlerin öğretim aracı olarak teknolojinin kullanımına yönelik tutumlarının pozitif olduğunu ortaya koymuştur. Başka bir çalışmada Gunter and Reeves (2017) mobil öğrenmenin göreceli değerine ilişkin öğretmenlerin görüşlerini belirlemek üzere karma araştırma desenini kullanarak bir çalışma gerçekleştirmişlerdir. Çalışmaya büyük çoğunluğunu kadın öğretmenlerin oluşturduğu ve anaokulundan lise son sınıfa kadar farklı düzeylerde öğretmenlik yapan 139 öğretmen mesleki gelişim kursuna katılmıştır. Mesleki gelişim kursu öğretim tasarımcıları ve dijital medya uzmanlarınca verilmiştir. Çalışmaya ilişkin veriler çalışma öncesinde ve sonrasına uygulanan mobil öğrenme anketi aracılığı ile elde edil- 
miştir. Anket aracılığı ile öğretmenlerin sınıf içinde ve dışında öğrenci öğrenmesine ilişkin tutumları incelenmiştir. Ayrıca çalışmada öğretmenlerin uygulamalarında mobil araçları kullanmalarına ilişkin tutumları da araştırılmıştır. Çalışma sonuçları mesleki gelişim kursunun öğretmenlerin mobil öğrenmeye ilişkin tutumlarını olumlu yönde etkilediğini ortaya koymuştur. Ayrıca, çalışma sonuçları göstermiştir ki; mesleki gelişim kursu süresince uygulamalara katılma fırsatına erişen öğretmenlerin tutumlarının yanında sınıflarında teknolojiyi kullanmaya yönelik isteklerinin de arttı̆̆ gözlenmiştir.

Bilgiye erişim internetin yaygınlaşması ile yeni bir boyut kazanmıştır. Günümüzde yaygın olarak her bireyin kullandığı teknolojilerden olan, mobil cihazların eğitim-öğretim amaçlı kullanımına yönelik farklı çalışmalar gerçekleştirilmiştir. Mobil teknolojileri öğrenme amacı ile günümüzde ve gelecekte nasıl kullandıklarını anlamak amacı ile, Oz (2014) çalışmasında İngilizce öğretmenliği bölümünde okuyan 144 son sınıf öğrencisinden anket aracılığı ile veriler toplamıştır. Çalışma sonucunda öğrencilerin çoğunluğunun mobil cihazlara sahip olduğu ve bu cihazları öğrenme amaçlı kullandıkları ve ileride kullanacakları saptanmıştır. Tekerek, Altan ve Gündüz (2014) çalışmalarında FATİH projesi kapsamında ülkemizde öğrencilere dağıtılan tablet bilgisayara yönelik 9. sinıf öğrencilerinin tutumlarını incelemiştir. Çalışmada 220 öğrenciden tutum ölçeği aracılığı ile veriler toplanmıştır. Çalışma sonucunda öğrencilerin tablet bilgisayarları kullanmaktan keyif aldıkları saptamıştır. Ayrıca öğrencilerin tutumlarının cinsiyete göre değişim göstermediği, fakat evinde bilgisayarı bulunan öğrencilerin diğerlerine göre tablet bilgisayarlara yönelik daha olumlu tutum sergiledikleri saptanmıştır. Benzer şekilde tablet bilgisayarların sınıf içinde kullanımının etkinliğini araştırmak amacı ile, Pruet, Ang ve Farzin (2016) çalışmalarında 2012 yılında Tayvan Devletinin birinci sınıf öğrencilerine eğitim kalitesinin standardize edilmesi ve dijital farkın kapatılması amacı ile dağıtılan 800,000 tablet bilgisayar projesini incelemek için bir çalışma gerçekleştirmişlerdir. Çalışmaya ilişkin veriler tablet bilgisayarları kullanan ve ekonomik olarak geri kalmış bölgelerde yaşayan 213 birinci sinıf öğrencisinden anketler aracılığı ile toplanmıştır. Çalışma sonucunda katılımcıların teknoloji deneyimi ve tablet bilgisayar kullanımına ilişkin tutumlarının cinsiyete göre değişmediği 
saptanmıştır. Bununla birlikte kırsalda yaşayan öğrencilerin şehirde yaşayanlara göre tablet kullanımı konusunda daha istekli oldukları saptanmıştır. Son olarak ise öğrencilerin teknoloji deneyimlerinin ve isteklerinin, öğrencilerin akademik performanslarını etkilediğini saptanmıştır. Başka bir araştırmada ise, Al-Emran, Elsherif ve Shaalan (2016), Umman ve Birleşik Arap Emirlikleri'ndeki üniversite öğrenci ve öğretim elemanlarının mobil öğrenmeye ilişkin tutumlarını incelemişlerdir. Beş farklı üniversiteden 383 öğrenci ve 54 öğretim elemanı çalışmaya katılmıştır. Çalışmada farklı faktörler açısından öğrenci ve öğretim elemanlarının mobil öğrenmeye ilişkin tutumları karşılaştırılmıştır. Çalışma sonuçları mobil cihazlara sahip olan öğrencilerin mobil öğrenmeye ilişkin tutumlarının bu cihazlara sahip olmayanlara göre daha pozitif olduğunu ortaya koymuştur. Ayrıca öğrencilerin tutumlarının cinsiyet, bölüm ve lisansüstü ya da lisans öğrenim düzeylerine göre farklılık göstermediği saptanmıştır. Öğretim elemanları açısından çalışma sonuçları göstermiştir ki; Bütün öğretim elemanlarının mobil öğrenmeye ilişkin tutumları olumludur. Ayrıca öğretim elemanlarının mobil öğrenmeye ilişkin tutumlarının mesleki deneyim ve unvanlarına göre farklılık göstermediği saptanmıştır. Başka bir çalışmada, Heflin, Shewmaker ve Nguyen (2017), mobil cihazların kullanıldığ1 ve kullanılmadığı işbirlikçi öğrenme ortamlarında katılımcıların işbirlikçi öğrenmeye ilişkin tutumlarını karşılaştırmıştır. Çalışma 159 üniversite öğrencisi ile gerçekleştirilmiştir. Çalışma soncunda mobil cihazlar ile öğrencilerin işbirlikçi öğrenmeye ilişkin pozitif algılarının bağlantılı olduğu saptanmakla birlikte öğrencilerin sınıf içerisindeki etkileşiminin azaldığı sonucuna ulaşılmıştır.

Mobil öğrenmenin kullanımını etkileyecek etmenler ve mobil öğrenmeye yönelik tutumu açıklama inceleyen çalışmalarda sürdürülmüştür. Hsieh ve Tsai (2017) çalışmalarında Tayvan'daki öğretmenlerin mobil öğrenme kavramına ilişkin görüşlerini belirlemek üzere fenomenografik bir araştırma gerçekleştirmişlerdir. Çalı̧̧mada lise son sınıflarda öğretmenlik yapan 15 öğretmenden yarı yapılandırılmış görüşmeler ile veriler toplanmıştır. Veri analizi sonucunda mobil öğrenmeye ilişkin altı kategorik kavram ortaya çıkartılmıştır. Bu kavramlar, öğrencilerin tercihleri ile buluşması, sınıfların daha verimli olması, öğrenmenin zenginleştirilmesi, geleneksel öğretimden ayrılması, ögrencinin sahiplenmesine odaklanması ve 
öğrenmeyi okulun ötesine uzatmasıdır. Bu kavramların derlenmesi sonucunda ise, öğretmenleri mobil öğrenmeye ilişkin ana fikirlerinin verimlilik ve üretkenliği arttırma olduğu saptanmıştır. Başka bir çalışmada öğrencilerin mobil teknolojileri öğrenme amacı ile kullanmalarını etkileyecek öğrenci davranışlarını etkileyen değişik faktörleri ve güdüleyicileri incelemek amacı ile Briz-Ponce, vd. (2017) tarama yöntemini kullanmışlardır. Çalışmaya ilişkin veriler Portekiz'deki bir devlet üniversitesinde tıp eğitimi alan 160 öğrenciden toplanmıştır. Çalışma sonucunda tıp öğrencilerinin mobil öğrenme ve uygulamalarını kullanmaya ilişkin algılarının ve tutumlarının olumlu olduğu saptanmıştır. Ayrıca çalışma sonuçları sosyal etkinin öğrencilerin mobil öğrenmeyi kullanmalarında önemli bir faktör olduğunu ortaya koymuştur.

Mobil öğrenmenin etkinliğinin incelenmesi amacı ile yapılan çalışmalarında Heflin, Shewmaker and Nguyen (2017) yarı deneysel araştırma desenini kullanarak mobil teknoloji içeren ve içermeyen işbirlikçi öğrenme ortamlarında öğrenci katılımını, eleştirel düşünme düzeyini ve işbirlikçi öğrenmeye ilişkin öğrenci tutumlarını incelemişlerdir. Çalışmaya çoğunluğu kadın öğrencilerden oluşan 159 üniversite birinci sınıf öğrencisi katılmıştır. Çalışma sonuçları göstermiştir ki; mobil teknolojiler işbirlikçi öğrenme için kullanışlı araçlar olmakla birlikte öğrenme amaçlı her teknoloji kullanımı öğrencilerin dikkatinin dağılması ve öğrenme aktivitelerine katılmaması davranışını sergileme riskini de bünyesinde barındırmaktadır. Ayrıca çalışma mobil cihazları kullanan öğrencilerin eleştirel düşünme becerilerinin kâğıt kalem veya bilgisayar kullanan gruplardaki öğrencilerinkine oranla daha düşük düzeyde olduğunu göstermiştir. Başka bir çalışmada Martin ve Ertzberger (2013) mobil cihazla ile verilen öğrenme ile bilgisayar tabanlı verilen öğrenmenin üniversite öğrencilerinin başarı ve tutumlarına olan etkilerini incelemişlerdir. Çalışmada bilgisayar tabanlı öğrenme grubunda olan öğrencilerin başarılarının mobil öğrenme grubunda olan öğrencilerden daha yüksek düzeyde olduğu saptanmıştır. Fakat tutum açısından incelendiğinde mobil cihazlar ile verilen öğrenme ortamında yer alan öğrencilerin tutum değerlerinin bilgisayar tabanlı öğrenme ortamını kullanan öğrencilerden daha yüksek düzeyde olduğu gözlenmiştir.

Yukarıdaki araştırmalar değerlendirildiğinde Mobil öğrenme çalışmalarına bir yönelim olduğu anlaşılmaktadır. Diğer yandan Hwang ve 
Chang (2011) mobil öğrenme ortamı için geliştirdikleri formatif değerlendirmenin etkinliğini incelemişlerdir. Çalışma beşinci sınıf öğrencileri ile gerçekleştirilmiştir. Kontrol grubunda bulunan öğrenciler geleneksel mobil öğrenme yaklaşımını kullanır iken deney grubunda bulunan öğrenciler ise formatif değerlendirmenin kullanıldığı mobil öğrenme ortamını yerel kültür dersinde kullanmışlardır. Çalışma sonuçları formatif değerlendirmenin kullanıldığı mobil öğrenme ortamlarındaki öğrencilerin ilgi, tutum ve öğrenme başarılarında artış olduğunu göstermiştir.

\section{Araştırmanın Amacı}

Bu çalışmada, öğretmen adaylarının mobil öğrenmeye ilişkin tutumlarının belirlenmesi hedeflenmiştir. Araştırma amacına ulaşmak için aşağıdaki araştırma soruları geliştirilmiştir:

1. Katılımcıların mobil öğrenmeye yönelik tutumları ve tutum alt faktörlerinden (avantaj, sınırlılık, kullanışlılık, özgürlük) cinsiyete göre farklılık göstermekte midir?

2. Katılımcıların mobil öğrenmeye yönelik tutumları ve tutum alt faktörlerinden (avantaj, sınırlılık, kullanışlılık, özgürlük) alt faktörleri öğrenim gördükleri lisans programlarına göre farklılık göstermekte midir?

3. Katılımcıların mobil öğrenmeye yönelik tutumları ve tutum alt faktörlerinden (avantaj, sınırlılık, kullanışlılık, özgürlük) alt faktörleri mobil cihaz üzerinden haftalık internet erişim sürelerine göre farklılık göstermekte midir?

\section{Araştırmanın Önemi}

Nitelikli bilgiye ulaşmak eğitim öğretimin verimliliğinde önemli yer tutar. Bireyde gerçekleşen öğrenmeyi desteklemek amacı ile dışarıdan aktarılan bilgiye ulaşım vasıtalarında değişimler yaşanmaktadır. Mobil öğrenmeye ilişkin öğrencilerin tutumları mobil öğrenme sistemlerinin yaygın olarak kullanılması açısından önemlidir (Al-Emran, Elsherif ve Shaalan, 2016). Akıllı cep telefonları ve tabletler ile hayatımıza giren yeni bilgi aktarım vasıtalarının eğitim öğretim ortamında bilgi aktarımı amacı ile kullanıl- 
masında, öğretmen adaylarının bu yeni öğrenme yaklaşımına ilişkin tutumlarının belirlenmesi önem kazanmaktadır. Araştırmacılar öğrencilerin ve eğitimcilerin mobil öğrenmeyi kullanmaya hazır olup olmadıklarını belirlemek amacı ile mobil öğrenmeye ilişkin tutumlarının belirlenmesinin önemli ve incelenmesi gereken bir konu olduğuna vurgu yapmaktadirlar (Al-Emran, Elsherif ve Shaalan, 2016).

\section{Yöntem}

Bu çalışmada öğretmen adaylarının mobil öğrenmeye ilişkin tutumlarının saptanması amacı ile betimsel araştırma modeli seçilmiştir. Çalışmada tek zamanlı verilerin toplandığ 1 kesitsel anket araştırma deseni (Cross-Sectional Survey Design) kullanılmıştır (Creswell, 2002). Çelik (2013) tarafından geliştirilen M-öğrenme tutum ölçeği veri giriş hatalarını ortadan kaldırmak amacı ile optik form olarak hazırlatılmıştır. Optik form olarak hazırlatılan M-öğrenme tutum ölçeği öğretmen adaylarınca doldurulmuş ve optik okuyucu tarafından veriler bilgisayar ortamına aktarılmıştır. Böylece veri girişinden kaynaklanabilecek hatalar asgari düzeye indirgenmesi sağlanmıştır.

\section{Çalışmanın Popülasyonu ve Örneklemi}

Çalışmanın popülasyonunu Eğitim Fakültelerinde öğrenim gören öğretmen adayları oluşturmuştur. Çalışmanın hedef popülasyonunu ise Batı Karadeniz'deki bir devlet üniversitensin eğitim fakültesinde öğrenim gören öğretmen adaylarından oluşmaktadır. Eğitim Fakültesi'nde öğrenci alımı yapılan Sınıf, Sosyal Bilgiler, Okul Öncesi, İlköğretim Matematik, Türkçe Ve Zihinsel Engelliler Öğretmenliği bölümlerinde öğrenim gören 1004 öğretmen adayı çalışmaya dâhil edilmiştir. Çalışmaya ilişkin örneklem seçiminde tam örnekleme yöntemi kullanılmış ve bu amaçla Eğitim Fakültesi'nde öğrenim gören yaklaşık 2200 öğretmen adayının tamamına ulaşılarak gönüllülük esasına göre çalışmaya katılımları istenmiştir. Mobil öğrenmeye yönelik tutum anketini doldurarak toplamda çalışmaya 1104 öğretmen adayı katılmayı kabul etmiştir. Çalışmaya katılan ve ankette cinsiyetini belirten 993 öğretmen adayının \% 22,5'i erkek ve \%77,5'i kadın öğretmen adaylarından oluşmuştur. 


\section{Veri Toplama Araci}

Çalışmaya ilişkin veriler Çelik (2013) tarafından geliştirilen M-öğrenme tutum ölçeği aracılığı ile toplanmıştır. Ölçek 21 maddeden oluşmaktadır. Ölçekte yer alan her bir maddeye ilişkin olarak Kesinlikle Katılmıyorum, Katılmıyorum, Kararsızım, Katılıyorum, Kesinlikle Katılıyorum cevap seçeneklerini içeren beşli likert tipinde ölçek kullanılmıştır. M-öğrenme tutum ölçeği dört faktörden oluşmaktadır. Bu faktörler M-Öğrenmenin avantajları, M-Öğrenmede sinırlılıklar, M-Öğrenmede kullanışlılık ve MÖğrenmede özgürlük faktörleridir. Çelik (2013) tarafından anketin Cronbach Alpha iç tutarlık katsayısı 0,881 olarak hesaplanmıştır. Bu çalışmada toplanan verilerin analizi sonucunda Cronbach Alpha ile ifade edilen iç tutarlılık değerlerine göre ölçeğin toplam güvenilirliğinin göstergesi Cronbach Alpha değeri 0,885 olarak hesaplanmıştır.

Ölçekte bulunan faktörler sırasıyla m-Öğrenmenin avantajları, m-Öğrenmede sinırlılıklar, m-Öğrenmede kullanışlılık ve m-Öğrenmede özgürlük olarak isimlendirilmiştir. Ölçek maddelerinde 5 olumsuz (sınırlılık boyutu altında) ve 16 olumlu madde bulunmaktadır. Çalışma kapsamında yapılan Doğrulayıcı Faktör Analiz (DFA) sonuçlarına göre veri seti ile ölçeğin faktör yapısı arasında iyi uyum bulunmuştur. DFA analizi sonucunda elde edilen ölçek modeli Şekil 1'de verilmiştir.

Öğretmen adaylarından elde edilen veriler ile faktör yapısının uyumunu incelemek için yapılan DFA analizleri sonucunda (Tablo 1), Uyum İyiliği İndeksi (Goodness of Fit Index; GFI), Karşılaştırmalı Uyum İndeksi (Comparative Fit Index; CFI) değerlerinin istenilen kriter değer olan 0,90 değerinin üstünde olduğu görülmektedir. Diğer bir indeks olan Standartlaştırılmış Hata Kareler Ortalaması Kare Kökü (Standartion Root Mean Square Residual; SRMR) ise "0" değerine yaklaştıkça iyi uyum anlamına gelmektedir. Byrne (2010) SRMR indeks değerinin 0,05 altında bulunmasının modelde yer alan korelasyonların veri seti ile uyum gösterdiğini ifade etmektedir. Bu çalışma kapsamında elde edilen SRMR değeri "0" değerine oldukça yakın olduğu görülmektedir. Diğer bir indeks olan Yaklaşık Hataların Ortalama Karekökü (Root Mean Square Error of Approximation; RMSEA) ise modelin serbestlik derecesine göre ne kadar karmaşık olduğunu ifade eden bir ölçüttür. 


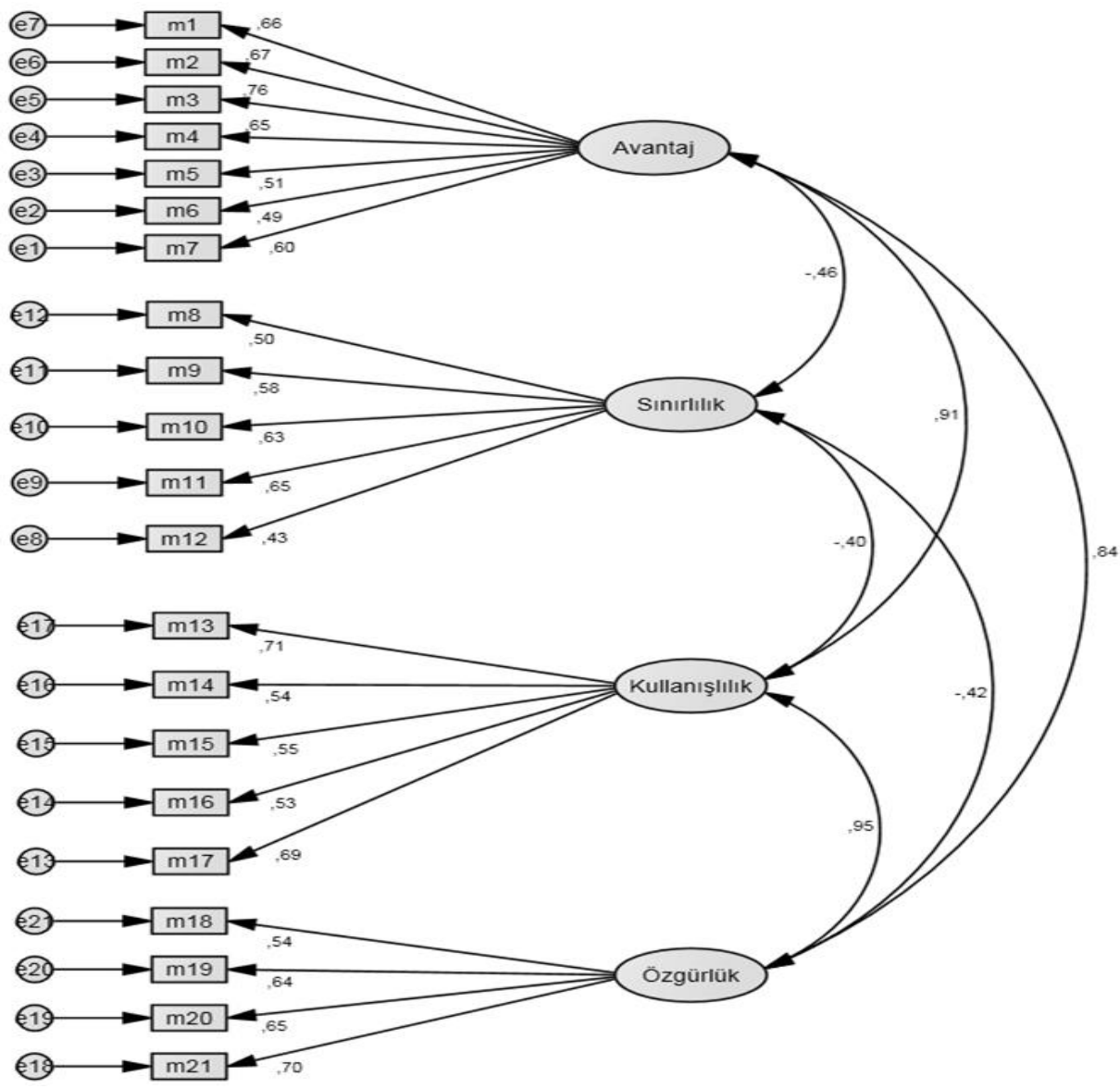

Şekil 1. DFA analizi sonucunda elde edilen M-öğrenme tutum ölçeği modeli

Tablo 1. Modele İlişkin İyilik Uyum İndeks Değerleri

\begin{tabular}{lllllll}
\hline Model & Ki-kare & Sd & GFI & CFI & SRMR & RMSEA \\
\hline 4 boyut- 21 madde & 638,258 & 1830 &, 94 &, 93 &, 05 &, 05 \\
\hline
\end{tabular}

Hu ve Bentler (1999) RMSEA uyum indeksi için 0,06 değerinin altında olan modellerin iyi uyum; 0,08 ile 0,1 değerinin arasında olan modellerin ise kabul edilebilir düzeyde olduğunu ifade etmektedir. Bu çalışma kapsamında kullanılan ölçeğin RMSEA değeri istenilen kritik değerin altında bulunmuştur. Sonuç olarak, Tablo 2 incelendiğinde Cronbach Alpha ile 
ifade edilen iç tutarlılık değerlerine göre ölçeğin toplam güvenilirliğinin göstergesi Cronbach Alpha değeri 0,885 olarak hesaplanmıştır. Bu değer ölçeğin güvenilir olduğunu göstermektedir.

Tablo 2. Ölçeğe ilişkin Cronbach Alpha değerleri

\begin{tabular}{llllll}
\hline Faktör & Avantaj & Sinırlılık & Kullanışlılık & Özgürlük & $\begin{array}{l}\text { Genel Orta- } \\
\text { lama }\end{array}$ \\
\hline $\begin{array}{l}\text { Cronbach } \\
\text { Alpha }\end{array}$ & 0.807 & 0.692 & 0.744 & 0.722 & 0.885 \\
\hline
\end{tabular}

\section{Verilerin Analizi}

Araştırma sorularının analizinde katılımcı sayısının fazla olmasından ötürü Merkezi Limit Teoremine göre verilerin normal dağıldığı kabul edilerek parametrik testlerden bağımsız örneklemler için t-testi, ANOVA testi, Tamhane's T2 ve Bonferroni Post Hoc testleri kullanılmıştır. Bu testler ile araştırma sorularında belirtilen iki ve daha fazla gruba ait verilerin karşılaştırılması gerçekleştirilmiştir. Çalışmada kullanılan bütün istatistiksel analizler 0,05 anlamlılık düzeyinde yapılmıştır. Çalışmaya ilişkin analizlerin tamaminda SPSS (Statistical Package for the Social Sciences) programı ve AMOS (Analysis of A Moment Structures) kullanılmıştır.

\section{Bulgular}

\section{Demografik Bilgiler}

Çalışmaya Mobil öğrenmeye yönelik tutum anketini dolduran 1104 öğretmen adayı katılmıştır. Çalışmaya katılan 1104 öğretmen adayından 993 tanesi cinsiyetini ankette belirtmiştir. Çalışmaya katılan öğretmen adaylarının cinsiyete göre dağılımları Tablo 3'de verilmiştir.

Tablo 3. Cinsiyete Göre Öğretmen Adaylarının Dă̆ılımı

\begin{tabular}{lll}
\hline Cinsiyet & $\mathbf{N}$ & \% \\
\hline Kadın & 770 & 77,5 \\
Erkek & 223 & 22,5 \\
Toplam & 993 & 100 \\
\hline
\end{tabular}


Tablo 4. Bölümlere Göre Öğretmen Adaylarının Dağılımı

\begin{tabular}{lll}
\hline Bölümler & N & \% \\
\hline Sinıf Öğretmenliği & 360 & 35,9 \\
Sosyal Bilgiler Öğretmenliği & 124 & 12,4 \\
Okul Öncesi Öğretmenliği & 261 & 26,0 \\
İlköğretim Matematik Öğretmenliği & 129 & 12,8 \\
Türkçe Öğretmenliği & 42 & 4,2 \\
Zihin Engelliler Öğretmenliği & 88 & 8,8 \\
Toplam & 1004 & 100,0 \\
\hline
\end{tabular}

Tablo 5. Sınıflara Göre Öğretmen Adaylarının Dă̆ılımı

\begin{tabular}{lll}
\hline Siniflar & N & \% \\
\hline 1.Sinif & 324 & 32,3 \\
2. Sinif & 221 & 22,0 \\
3. Sinif & 254 & 25,3 \\
4. Sinif & 205 & 20,4 \\
Toplam & 1004 & 100,0 \\
\hline
\end{tabular}

Çalışmaya katılan ve ankette cinsiyetini belirten 993 öğretmen aday1nın \% 22,5'i erkek ve \%77,5'i kadınlardan oluşmuştur. Eğitim Fakültesi'nde öğretmen adaylarının öğrenim gördükleri bölümlere göre anketi dolduran 1004 katılımcının dağılımının \%36'sı Sınıf Öğretmenliği, \%12'si Sosyal Bilgiler Öğretmenliği, \%26,'s1 Okul Öncesi Öğretmenliği, \%13'ü İlköğretim Matematik Öğretmenliği, \%4'ü Türkçe Öğretmenliği, \%9'u Zihinsel Engelliler Öğretmenliği bölümlerinde öğrenim görenlerden oluşmaktadır. Tablo 4'e göre katılımcıların yarısından fazlası Sınıf Öğretmenliği ve Okulöncesi Öğretmenliği bölümünde okuyan öğretmen adaylarından oluşmaktadır. Verilerin toplandığı öğretmen adaylarının sınıflara göre dağılımında ise, \%32'si birinci sınıf, \%22'si ikinci sınıf, \%25'i üçüncü sınıf ve \%21'i ise dördüncü sınıfta okuyan katılımcılardan oluşmaktadır. Tablo 5' e göre çalışmaya en fazla katılım birinci sınıfta okuyan öğretmen adaylarından oluşmuştur.

\section{Cinsiyete Göre Mobil Öğrenmeye Yönelik Tutumların Karşılaştırılması}

Öğretmen adaylarının Mobil öğrenmeye yönelik tutumlarının cinsiyete göre değişim gösterip göstermediğinin saptanması amacı ile bağımsız örneklemler için t-test kullanılmıştır. 
Tablo 6. Mobil Öğrenmeye Yönelik Tutumun Cinsiyete Göre Karşılaştırılması

\begin{tabular}{llllllll}
\hline & Cinsiyet & $\mathbf{N}$ & $\mathbf{X}$ & Sd & Sd & t & P \\
\hline $\begin{array}{l}\text { Mobil öğren- } \\
\text { meye yönelik }\end{array}$ & Kadın & 770 & 3,40 & 0,47 & 991 & 1,54 & 0,065 \\
tutum & Erkek & 223 & 3,34 & 0,52 & & & \\
\hline
\end{tabular}

Analiz sonuçlarına göre öğretmen adaylarının Mobil öğrenmeye yönelik tutumlarında cinsiyete göre bir farklılık saptanmamıştır ( $\mathrm{t} 991=1.54, \mathrm{p}$ $>0.05$ ) (Tablo 6).

Mobil öğrenme alt faktörlerinin cinsiyete göre karşılaştırmasında bağımsız örneklemler için t-test'i kullanılmıştır.

Tablo 7. Mobil Öğrenmeye Yönelik Tutum Değişkenin Alt Faktörlerinin Cinsiyete Göre Karşılaştırılması

\begin{tabular}{|c|c|c|c|c|c|c|c|}
\hline Alt Faktörler & Cinsiyet & $\mathbf{N}$ & $x$ & Sd & SD & $t$ & $\mathrm{p}$ \\
\hline \multirow[t]{2}{*}{ Avantaj } & Kadın & 770 & 3,41 & 0,72 & \multirow{2}{*}{991} & \multirow{2}{*}{1,32} & \multirow{2}{*}{0,17} \\
\hline & Erkek & 223 & 3,33 & 0,82 & & & \\
\hline \multirow[t]{2}{*}{ Kullanışlılık } & Kadın & 770 & 3,52 & 0,71 & \multirow{2}{*}{991} & \multirow{2}{*}{0,28} & \multirow{2}{*}{0,77} \\
\hline & Erkek & 223 & 3,5 & 0,80 & & & \\
\hline \multirow[t]{2}{*}{ Özgürlük } & Kadın & 770 & 3,59 & 0,77 & \multirow{2}{*}{991} & \multirow{2}{*}{0,47} & \multirow{2}{*}{0,65} \\
\hline & Erkek & 223 & 3,56 & 0,77 & & & \\
\hline \multirow[t]{2}{*}{ Sinırlılık } & Kadın & 770 & 2,86 & 0,71 & \multirow{2}{*}{991} & \multirow{2}{*}{$-1,68$} & \multirow{2}{*}{0,092} \\
\hline & Erkek & 223 & 2,96 & 0,78 & & & \\
\hline
\end{tabular}

Analiz sonuçlarına göre M-Öğrenmenin avantajları ( $\mathrm{t} 991=1.32, \mathrm{p} \geq$ 0.05), M-Öğrenmenin kullanışlılığ1 ( $\mathrm{t} 991=0.28, \mathrm{p}>0.05$ ), M-Öğrenmede özgürlük ( $\mathrm{t} 991=0.47, \mathrm{p}>0.05$ ) ve M-Öğrenmenin sinırlılıkları (t $991=-1.68$, $\mathrm{p}>0.05)$ cinsiyete göre karşılaştırıldı̆̆ında herhangi bir fark saptanmamıştır (Tablo 7).

\section{Öğretmen Adaylarının Bölümlerine Göre Mobil Öğrenmeye Yönelik Tutumlarının Karşılaştırılması}

Öğretmen adaylarının Mobil öğrenmeye yönelik tutumlarının öğrenim gördükleri bölüme göre değişim gösterip göstermediğinin saptanması amacı ile ANOVA testi kullanılmıştır. Analiz sonuçlarına göre öğretmen 
adaylarının Mobil öğrenmeye yönelik tutumlarının bölümlere göre farklılık gösterdiği saptanmıştır ( F $(5,998)=5,1, \mathrm{p}<0,05)$ (Tablo 8).

Tablo 8. Mobil Öğrenmeye Yönelik Tutumun Bölümlere Göre Karşılaştırılması

\begin{tabular}{lllllll}
\hline & Bölümler & $\begin{array}{l}\text { Kareler } \\
\text { Toplamı }\end{array}$ & Sd & $\begin{array}{l}\text { Ortalamanın Ka- } \\
\text { resi }\end{array}$ & F & p \\
\hline Mobil öğren- & Gruplar arası & 5,85 & 5 & 1,17 & 5,1 & 0,0 \\
meye yönelik & $\begin{array}{l}\text { Grup içi } \\
\text { tutumun }\end{array}$ & 228,8 & 998 &, 22 & & \\
\hline
\end{tabular}

Mobil öğrenmeye yönelik tutumun alt faktörlerinin bölümlere göre değişim gösterip göstermediğinin saptanması amacı ile ANOVA testi kullanılmıştır. Analiz sonuçlarına göre M-Öğrenmenin avantajları $(F(5,998)=$ 5,5, p < 0,05), M-Öğrenmede kullanışlılık $(\mathrm{F}(5,998)=2,3, \mathrm{p}<0,05)$ ve MÖğrenmede özgürlük ( $F(5,998)=3,3, p<=0,05)$ alt faktörlerinde bölümlere göre anlamlı farklar saptanmıştır (Tablo 9). Fakat M-Öğrenmede s1nırlılık $(F(5,998)=0,38 p>0,05)$ alt faktöründe bölümlere göre anlamlı fark saptanmamıştır (Tablo 9).

Tablo 9. Mobil Öğrenmeye Yönelik Tutumun Alt Faktörlerinin Bölümlere Göre Karşılaştırılması

\begin{tabular}{|c|c|c|c|c|c|c|}
\hline Alt Faktörler & Bölümler & $\begin{array}{l}\text { Kareler } \\
\text { Toplamı }\end{array}$ & Sd & $\begin{array}{l}\text { Ortalamanın } \\
\text { Karesi }\end{array}$ & $F$ & $p$ \\
\hline \multirow{3}{*}{ Avantaj } & Gruplar arası & 15,41 & 5 & 3,08 & 5,5 & $0,0^{*}$ \\
\hline & Grup içi & 558,9 & 998 &, 56 & & \\
\hline & Toplam & 574,4 & 1003 & & & \\
\hline \multirow{3}{*}{ Kullanışlılık } & Gruplar arası & 7,09 & 5 & 1,41 & 2,6 &, $022^{*}$ \\
\hline & Grup içi & 534,5 & 998 &, 53 & & \\
\hline & Toplam & 541,6 & 1003 & & & \\
\hline \multirow{3}{*}{ Özgürlük } & Gruplar arası & 9,9 & 5 & 1,99 & 3,3 & $0,05^{*}$ \\
\hline & Grup içi & 594,7 & 998 &, 59 & & \\
\hline & Toplam & 604,7 & 1003 & & & \\
\hline \multirow{3}{*}{ Sinırlılık } & Gruplar arası & 1,03 & 5 & ,206 & ,38 & 86 \\
\hline & Grup içi & 537,6 & 998 &, 539 & & \\
\hline & Toplam & 538,7 & 1003 & & & \\
\hline
\end{tabular}

Analiz sonuçlarına göre M-Öğrenmenin avantajları ( F $(5,998)=5,5$, p $<0,05)$, M-Öğrenmede kullanışlilık $(\mathrm{F}(5,998)=2,3, \mathrm{p}<0,05)$ ve M-Öğrenmede özgürlük $(\mathrm{F}(5,998)=3,3 \mathrm{p}<=0,05)$ alt faktörlerinde bölümlere göre anlamlı farklar saptanmıştır (Tablo 9). Fakat M-Öğrenmede sınırlılıklar (F 
$(5,998)=0.38, p>0.05)$ alt faktöründe bölümlere göre anlamlı fark saptanmamıştır (Tablo 9).

Tablo 10. Mobil Öğrenmeye Ve Alt Faktörlerine Yönelik Post Hoc Test Karşılaştormasi

\begin{tabular}{|c|c|c|c|c|c|}
\hline Faktör & Avantaj & Sinurlılık & Kullanışlılık & Özgürlük & $\begin{array}{l}\text { Genel Orta- } \\
\text { lama }\end{array}$ \\
\hline Bölüm & $\begin{array}{l}\text { Okul Öncesi } \\
- \text { Matematik } \\
\text { (B) } \\
\text { Matematik - } \\
\text { Zihin Eng. } \\
\text { (B) } \\
\text { Zihin Eng. - } \\
\text { Türkçe (B) }\end{array}$ & - & $\begin{array}{l}\text { Zihin Eng. - } \\
\text { Türkçe (LSD) }\end{array}$ & $\begin{array}{l}\text { Okul Öncesi } \\
-\quad \text { Türkçe } \\
\text { (LSD) } \\
\text { Matematik - } \\
\text { Zihin Eng. } \\
\text { (LSD) } \\
\text { Zihin Eng. - } \\
\text { Türkçe } \\
\text { (LSD) }\end{array}$ & $\begin{array}{l}\text { Matematik } \\
\text { Zihin Eng. } \\
\text { (B) } \\
\text { Türkçe - Zi- } \\
\text { hin Eng. (B) }\end{array}$ \\
\hline
\end{tabular}

(B) Bonferroni Post Hoc, (LSD) LSD Post Hoc

Bonferroni Post Hoc karşılaştırmasına göre, Zihin Engelliler öğretmenliği bölümü öğretmen adaylarının $\mathrm{M}$-öğrenmeye ilişkin tutumlarının ( $X$ $=3,53$ ) Illköğretim Matematik Öğretmenliği bölümü öğretmen adaylarının tutumlarından $(X=3,27)$ daha yüksek olduğu saptanmıştır. Ayrıca Zihin Engelliler öğretmenliği bölümü öğretmen adaylarının M-öğrenmeye ilişkin tutumları $(X=3,53)$ Türkçe öğretmenliği bölümü öğretmen adaylarının tutumlarından $(X=3,18)$ daha yüksek bulunmuştur (Tablo 10 ve Tablo 11).

LSD (Least Significant Difference) test karşılaştırmasına göre, Zihin Engelliler öğretmenliği bölümü öğretmen adaylarının M-öğrenmenin kullanışlılık alt faktörüne ilişkin tutumları $(X=3,68)$ Türkçe öğretmenliği bölümü öğretmen adaylarının tutumlarından $(X=3,29)$ daha yüksek bulunmuştur (Tablo 10 ve Tablo 11).

LSD (Least Significant Difference) test karşılaştırmasına göre, Zihin Engelliler öğretmenliği bölümü öğretmen adaylarının M-öğrenmenin özgürlük alt faktörüne ilişkin tutumlarının $(X=3,75)$ Türkçe öğretmenliği bölümü öğretmen adaylarının $(X=3,28)$ ve İlköğretim Matematik öğretmenliği bölümü öğretmen adaylarının $\mathrm{M}$-öğrenmenin özgürlük alt faktörüne ilişkin tutumlarından $(X=3,45)$ daha fazla olduğu saptanmıştır. Ayrıca Okul Öncesi Öğretmenliği bölümü öğretmen adaylarının M-öğrenmenin 
özgürlük alt faktörüne ilişkin tutumları $(X=3,64)$ Türkçe Öğretmenliği bölümü öğretmen adaylarının tutumlarından $(X=3,28)$ daha fazladır (Tablo 10 ve Tablo 11).

Tablo 11. Mobil Öğrenmeye Ve Alt Faktörlerine Yönelik Ortalamalar

\begin{tabular}{|c|c|c|c|c|c|}
\hline Faktörler & Bölümler & $\mathbf{N}$ & $x$ & Sd(df) & Sh(SE) \\
\hline \multirow{6}{*}{$\begin{array}{l}\bar{\pi} \\
\text { 䒕 } \\
\text { Z }\end{array}$} & Sınıf Öğretmenliği & 360 & 3,39 & ,73 & ,03 \\
\hline & Sosyal Bilgiler Öğretmenliği & 124 & 3,39 & ,06 &, 06 \\
\hline & Okul Öncesi Öğretmenliği & 261 & 3,47 & ,76 &, 04 \\
\hline & $\begin{array}{l}\text { İlköğretim Matematik Öğret- } \\
\text { menliği }\end{array}$ & 129 & 3,18 & ,77 & ,06 \\
\hline & Türkçe Öğretmenliği & 42 & 3,08 & ,79 & ,12 \\
\hline & Zihin Engelliler Öğretmenliği & 88 & 3,6 & ,77 &, 08 \\
\hline \multirow{6}{*}{ 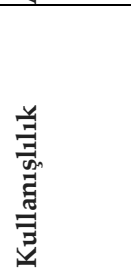 } & Sınıf Öğretmenliği & 360 & 3,48 & 71 & ,03 \\
\hline & Sosyal Bilgiler Öğretmenliği & 124 & 3,54 & 69 & ,06 \\
\hline & Okul Öncesi Öğretmenliği & 261 & 3,58 & ,76 &, 04 \\
\hline & $\begin{array}{l}\text { İlköğretim Matematik Öğret- } \\
\text { menliği }\end{array}$ & 129 & 3,42 & ,71 & ,06 \\
\hline & Türkçe Öğretmenliği & 42 & 3,29 & ,9 & ,13 \\
\hline & Zihin Engelliler Öğretmenliği & 88 & 3,68 & 66 & 07 \\
\hline \multirow{6}{*}{ 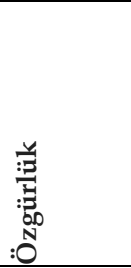 } & Sınıf Öğretmenliği & 360 & 3,56 & 76 & ,04 \\
\hline & Sosyal Bilgiler Öğretmenliği & 124 & 3,63 & 68 & 06 \\
\hline & Okul Öncesi Öğretmenliği & 261 & 3,64 & 82 &, 05 \\
\hline & $\begin{array}{l}\text { İlköğretim Matematik Öğret- } \\
\text { menliği }\end{array}$ & 129 & 3,45 & 74 & 06 \\
\hline & Türkçe Öğretmenliği & 42 & 3,28 & 87 & ,13 \\
\hline & Zihin Engelliler Öğretmenliği & 88 & 3,75 & ,72 & 07 \\
\hline \multirow{6}{*}{ 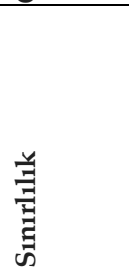 } & Sınıf Öğretmenliği & 360 & 2,85 & 75 & ,04 \\
\hline & Sosyal Bilgiler Öğretmenliği & 124 & 2,92 & 68 & ,06 \\
\hline & Okul Öncesi Öğretmenliği & 261 & 2,92 & 71 &, 05 \\
\hline & $\begin{array}{l}\text { İlköğretim Matematik Öğret- } \\
\text { menliği }\end{array}$ & 129 & 2,88 & 77 & ,06 \\
\hline & Türkçe Öğretmenliği & 42 & 2,85 & 78 & 13 \\
\hline & Zihin Engelliler Öğretmenliği & 88 & 2,88 & ,7 & 07 \\
\hline \multirow{6}{*}{ 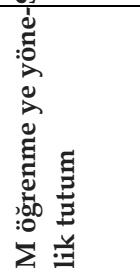 } & Sınıf Öğretmenliği & 360 & 3,39 & 44 & 0,02 \\
\hline & Sosyal Bilgiler Öğretmenliği & 124 & 3,4 & ,42 & 0,03 \\
\hline & Okul Öncesi Öğretmenliği & 261 & 3,43 &, 51 & 0,03 \\
\hline & $\begin{array}{l}\text { İlköğretim Matematik Öğret- } \\
\text { menliği }\end{array}$ & 129 & 3,27 &, 5 & 0,04 \\
\hline & Türkçe Öğretmenliği & 42 & 3,18 &, 57 & 0,08 \\
\hline & Zihin Engelliler Öğretmenliği & 88 & 3,53 &, 51 & 0,05 \\
\hline
\end{tabular}


Bonferroni Post Hoc test karşılaştırmasına göre, Zihin Engelliler öğretmenliği bölümü öğretmen adaylarının M-öğrenmenin avantajlarına ilişkin tutumlarının $(X=3,6)$ İlköğretim Matematik Öğretmenliği bölümü öğretmen adaylarının tutumlarından $(X=3,18)$ daha fazla olduğu saptanmıştır. Ayrıca Okul Öncesi Öğretmenliği bölümü öğretmen adaylarının Möğrenmenin avantajlarına ilişkin tutumlarının $(X=3,47)$ İlköğretim Matematik Öğretmenliği bölümü öğretmen adaylarının tutumlarından $(X=3,18)$ daha fazla olduğu saptanmıştır. İlaveten Zihin Engelliler öğretmenliği bölümü öğretmen adaylarının M-öğrenmenin avantajlarına ilişkin tutumlarının $(X=3,6)$ Türkçe öğretmenliği bölümü öğretmen adaylar1nın tutumlarından $(X=3,08)$ daha fazla olduğu saptanmıştır (Tablo 10 ve Tablo 11).

\section{Haftalık İnternet Erişim Sürelerine Göre Mobil Öğrenmeye Yönelik Tutumlarının Karşılaştııılması}

Öğretmen adaylarının Mobil öğrenmeye yönelik tutumlarının haftalık internet erişim sürelerine göre değişim gösterip göstermediğinin saptanması amacı ile ANOVA testi kullanılmıştır. Analiz sonuçlarına göre öğretmen adaylarının Mobil öğrenmeye yönelik tutumlarının haftalık internet erişim sürelerine göre farklılık gösterdiği saptanmıştır ( $F(4,953)=6,76$, p $<0,05)$ (Tablo 12).

Tablo 12. Mobil Öğrenmeye Yönelik Tutumun Haftalık İnternet Erişim Süresine Göre Karşılaştırılması

\begin{tabular}{lllllll}
\hline & $\begin{array}{l}\text { Haftalı internet eri- } \\
\text { şim süresi }\end{array}$ & $\begin{array}{l}\text { Kareler } \\
\text { Toplamı }\end{array}$ & Sd & $\begin{array}{l}\text { Ortalamanın } \\
\text { Karesi }\end{array}$ & F & p \\
\hline $\begin{array}{l}\text { Mobil öğ- } \\
\text { renmeye yö- }\end{array}$ & $\begin{array}{l}\text { Gruplar arası } \\
\text { Grup içi }\end{array}$ & 6,16 & 4 & 1,54 & 6,76 & 0,0 \\
$\begin{array}{l}\text { nelik tutu- } \\
\text { mun }\end{array}$ & \begin{tabular}{l} 
Toplam \\
\hline
\end{tabular} & 216,9 & 953 & 0,228 & & \\
\hline
\end{tabular}

ANOVA testi ile yapılan analiz sonuçlarına göre M-Öğrenmenin avantajları $(\mathrm{F}(4,953)=6.63, \mathrm{p}<0,05)$, M-Öğrenmede kullanışlılık $(\mathrm{F}(4,953)=$ 7.06, $\mathrm{p}<0,05)$ ve M-Öğrenmede özgürlük $(\mathrm{F}(4,953)=5.58, \mathrm{p}<0,05)$ alt faktörlerinde haftalık internet erişim süresine göre anlamlı farklar saptanmıştır (Tablo 13). Fakat ve M-Öğrenmede sınırlılık alt faktöründe haftalık 
internet erişim süresine göre anlamlı fark saptanmamıştır $(F(4,953)=1,5$, $\mathrm{p}>0,05)$ (Tablo 13).

Tablo 13. Mobil Öğrenmeye Yönelik Tutumun Alt Faktörlerinin Haftalık Internet Erişim Süresi Göre Karşılaştırılması

\begin{tabular}{|c|c|c|c|c|c|c|}
\hline Alt Faktörler & $\begin{array}{l}\text { Haftalık inter- } \\
\text { net erişim sü- } \\
\text { resi }\end{array}$ & $\begin{array}{l}\text { Kareler } \\
\text { Toplamı }\end{array}$ & $\mathrm{Sd}$ & $\begin{array}{l}\text { Ortalamanın } \\
\text { Karesi }\end{array}$ & $F$ & $p$ \\
\hline \multirow{3}{*}{ Avantaj } & Gruplar arası & 14,89 & 4 & 3,72 & 6,63 & $0,0^{*}$ \\
\hline & Grup içi & 535 & 953 & ,56 & & \\
\hline & Toplam & 549,9 & 957 & & & \\
\hline \multirow{3}{*}{ Kullanışlılık } & Gruplar arası & 14,9 & 4 & 3,73 & 7,06 & $0,0^{*}$ \\
\hline & Grup içi & 504 & 953 & ,52 & & \\
\hline & Toplam & 519 & 957 & & & \\
\hline \multirow{3}{*}{ Özgürlük } & Gruplar arası & 13,1 & 4 & 3,27 & 5,58 & $0,0^{*}$ \\
\hline & Grup içi & 558,9 & 953 &, 58 & & \\
\hline & Toplam & 572 & 957 & & & \\
\hline \multirow{3}{*}{ Sinırlılık } & Gruplar arası & 3,18 & 4 & ,79 & 1,5 & 0,199 \\
\hline & Grup içi & 505,4 & 953 &, 53 & & \\
\hline & Toplam & 508,6 & 957 & & & \\
\hline
\end{tabular}

M-öğrenmeye ilişkin tutumun ve alt faktörlerinin haftalık internet erişim süresine göre nasıl farklılık gösterdiğinin saptanması için Post Hoc testleri kullanılmıştır. Tamhane's T2 ve Bonferroni Post Hoc karşılaştırmasına göre, haftalık internet kullanım süresi 9 saat ve üzeri olan öğretmen adaylarının M-öğrenmeye ilişkin tutum ve tutumun alt faktörlerinden M-öğrenmenin avantajları ve M-öğrenmenin kullanışlılığına ilişkin tutumlarının haftalık internet kullanım süresi 4 saat ve altında olanlardan daha yüksek olduğu saptanmıştır (Tablo 11 ve Tablo 12). Buna karşın Möğrenmede özgürlüğe yönelik tutumların haftalık internet kullanım süresi 9 saat ve üzeri olanlarda 2 saat ve altında olanlara göre daha yüksek düzeyde olduğu saptanmıştır (Tablo 14 ve Tablo 15)

Tablo 14. Mobil Öğrenmeye Ve Alt Faktörlerine Yönelik Post Hoc Test Karşılaştırmast

\begin{tabular}{llllll}
\hline Faktör & Avantaj & Sinırlılık & Kullanışlılık & Özgürlük & $\begin{array}{l}\text { Genel Orta- } \\
\text { lama }\end{array}$ \\
\hline $\begin{array}{l}\text { Kullanım } \\
\text { Saati }\end{array}$ & $1-2 / 9+(\mathrm{T})$ & - & $1-2 / 9+(\mathrm{B})$ & $1-2 / 9+(\mathrm{B})$ & $1-2 / 9+(\mathrm{B})$ \\
& $3-4 / 9+(\mathrm{T})$ & & $3-4 / 9+$ & & $3-4 / 9+(\mathrm{B})$ \\
\hline
\end{tabular}

(B) Bonferroni Post Hoc, (T) Tamhane's T2, (LSD) LSD Post Hoc 
Tablo 15. Mobil Öğrenmeye Ve Alt Faktörlerine Yönelik Ortalamalar

\begin{tabular}{llllll}
\hline Alt Faktörler & $\begin{array}{l}\text { Haftalık internet erişim } \\
\text { süresi }\end{array}$ & $\mathbf{N}$ & $\mathbf{X}$ & Sd(df) & Sh(SE) \\
\hline Avantaj & 1-2 saat & 198 & 3,26 & 0,74 & 0,05 \\
& 3-4 saat & 185 & 3,27 & 0,71 & 0,05 \\
& 5-6 saat & 131 & 3,41 & 0,6 & 0,05 \\
& 7-8 saat & 99 & 3,37 & 0,77 & 0,07 \\
& 9 saat ve üzeri & 345 & 3,55 & 0,8 & 0,04 \\
\hline Kullanışlılık & 1-2 saat & 198 & 3,42 & 0,7 & 0,05 \\
& 3-4 saat & 185 & 3,41 & 0,65 & 0,04 \\
& 5-6 saat & 131 & 3,45 & 0,66 & 0,05 \\
& 7-8 saat & 99 & 3,41 & 0,81 & 0,08 \\
& 9 saat ve üzeri & 345 & 3,68 & 0,77 & 0,04 \\
\hline Özgürlük & 1-2 saat & 198 & 3,47 & 0,73 & 0,05 \\
& 3-4 saat & 185 & 3,49 & 0,73 & 0,05 \\
& 5-6 saat & 131 & 3,67 & 0,66 & 0,05 \\
& 7-8 saat & 99 & 3,44 & 0,76 & 0,07 \\
& 9 saat ve üzeri & 345 & 3,72 & 0,83 & 0,04 \\
\hline Sinırlllık & 1-2 saat & 198 & 2,85 & 0,67 & 0,04 \\
& 3-4 saat & 185 & 2,82 & 0,71 & 0,05 \\
& 5-6 saat & 131 & 2,84 & 0,64 & 0,05 \\
& 7-8 saat & 99 & 2,93 & 0,71 & 0,07 \\
& 9 saat ve üzeri & 345 & 2,95 & 0,79 & 0,04 \\
\hline 1-2 saat & 198 & 3,31 & 0,47 & 0,47 \\
& 3-4 saat & 185 & 3,32 & 0,44 & 0,44 \\
5-6 saat & 131 & 3,41 & 0,41 & 0,41 \\
nelik tutum & 7-8 saat & 99 & 3,32 & 0,48 & 0,48 \\
& 9 saat ve üzeri & 345 & 3,49 & 0,51 & 0,51 \\
\hline & & & &
\end{tabular}

\section{Tartışma ve Sonuç}

Mobil cihazların kullanımının yaygınlaştığı günümüz dünyasında (BrizPonce vd., 2017; Oz, 2014), eğitim öğretim amacı ile mobil cihazların kullanımı öncesinde yakın gelecekte öğretmen olacak öğretmen adaylarının mobil öğrenmeye yönelik tutumlarının belirlenmesi önemlidir (Al-Emran, Elsherif ve Shaalan, 2016). Öğretmen adaylarının mobil öğrenmeye ilişkin tutumlarını belirlemek amacı ile bu çalışma gerçekleştirilmiştir. Çalışma sonucunda öğretmen adaylarının mobil öğrenmeye ilişkin tutumlarının genel olarak olumlu olduğu saptanmıştır. Bu bulgular öğrencilerin mobil öğrenmeye istekli olduklarını ortaya koymaktadır. Ayrıca öğretmen adaylarının mobil öğrenmeye yönelik tutumlarının cinsiyete göre farklılık gös- 
termediği saptanmıştır. Farklı bağlamlarda mobil öğrenmeye ilişkin tutumları araştıran çalışmalarda da benzeri sonuçlar elde edilmiştir (Al-Emran, Elsherif ve Shaalan, 2016; Pruet, Ang ve Farzin, 2016). Çalışmaların sonuçları göstermektedir ki, öğretmen adaylarının mobil öğrenmeye karşı olan tutumları cinsiyete göre değişim göstermeksizin olumludur.

Öğretmen adaylarının öğrenim gördükleri öğretmenlik programlarına göre mobil öğrenmeye ilişkin tutumlarının değişim gösterdiği saptanmıştır. Buna göre Zihin Engelliler Öğretmenliği bölümünde öğrenim gören öğretmen adaylarının mobil öğrenmeye ilişkin tutumlarının İlköğretim Matematik ve Türkçe Öğretmenliği bölümlerindeki öğretmen adaylarından daha yüksek düzeyde olduğu saptanmıştır. Bu sonuçlar ileride Zihin Engelliler öğretmenlerinin mobil öğrenme araçlarını daha fazla kullanma eğiliminde olacağını işaret etmektedir. Bu noktadan hareketle Zihin Engelliler bölümünde mobil cihazlar ile kullanılabilecek içeriklerin hazırlanma çalışmalarının başlamasının gerekliliği anlaşılmaktadır.

Çalışma sonucunda öğretmen adaylarının mobil öğrenmeye yönelik tutumlarının öğretmen adaylarının haftalık internet kullanım sürelerine göre değişim gösterdiği saptanmıştır. Buna göre haftalık internet kullanım süresi fazla olan öğretmen adaylarının mobil öğrenmeye ilişkin tutumları, kullanım süresi daha az olanlara göre daha yüksek düzeydedir. Mobil cihazların ve internetin kullanım süresi mobil öğrenmeye ilişkin tutumu olumlu etkilemektedir (Al-Emran, Elsherif ve Shaalan, 2016; Tekerek, Altan ve Gündüz, 2014).

Çalışma sonuçları öğretmen adaylarının mobil öğrenmeye yönelik tutumlarının olumlu yönde olduğunu ortaya koymasına nazaran mobil öğrenmenin sınıf içerisindeki etkileşimi azalttığı (Heflin, Shewmaker ve Nguyen, 2017), mobil teknolojileri öğrenme amaçlı kullanımında bireylerin dikkatinin dağıldığı, bireylerin öğrenme aktivitelerine katılmama eğilimi gösterdikleri ve eleştirel düşünme becerilerinin daha düşük düzeyde olduğu (Heflin, Shewmaker ve Nguyen, 2017) ve bireylerin ders başarılarının daha düşük düzeyde olduğuna (Martin ve Ertzberger, 2013) dair çalışma sonuçları mobil öğrenmeye yönelik yapılacak tercihlerde göz ardı edilmemelidir. Her yenilikle birlikte gelen getiriler ve kaybettireceklerinin oranı dikkate alınarak mobil öğrenme kullanım tercihleri yapılmalıdır. 


\section{Öneriler}

Eğitim öğretim etkinliklerinin planlanmasında Zihin Engelliler bölümü öğretmen adaylarının mobil teknolojileri kullanabilecekleri aktivitelere yer verilmelidir. Ayrıca, bu çalışmada elde edilen verilerin toplandığı örneklem dörtte üçü kadın öğretmen adaylarından oluşan bir örneklemdir. Her ne kadar cinsiyet mobil öğrenmeye ilişkin tutumları etkileyen bir faktör olarak saptanmamış olsa da, ileride yapılacak çalışmalarda örneklem seçiminde kadın öğretmen adaylarının ve erkek öğretmen adaylarının oranının benzer olduğu örneklemler tercih edilerek çalışma tekrarlanmalıdır. Ayrıca sosyal etkinin bireylerin mobil öğrenmeyi kullanmalarında önemli bir faktör olduğu vurgulanmaktadır (Briz-Ponce, vd., 2017). Bu noktadan hareketle ileride yapılacak çalışmalarda mobil öğrenmeyi aktif olarak kullanan öğretmenlerin diğer meslektaşlarını nasıl etkilediği araştırılmalıdır. 


\title{
EXTENDED ABSTRACT
}

\section{The Attitude of Prospective Teachers Towards Mobile Learning}

\author{
Kemal Turgut - Elif Akdemir \\ Zonguldak Bülent Ecevit University
}

Different technologies have been used from past to present for the purpose of education and training. Today, the use of mobile devices is increasing (Briz-Ponce, Pereira, Carvalho, Juanes-Méndez, and GarcíaPeñalvo, 2017). Mobile devices that can be used for educational purposes nowadays range from smart phones used by individuals to tablet computers. The main use of mobile devices is communication, entertainment and access to information. The potential for mobile devices to be used for teaching purposes is important for students to access inside and outside the school. Mobile learning is defined as the use of mobile devices (PDA, mobile phone and iPod, etc.) for learning purposes (Sharples, Ar-nedilloSánchez, Milrad, and Vavoula, 2009). Learning through mobile devices allows students to collaborate and share ideas between and outside the school (Al-Emran, Elsherif and Shaalan, 2016).

Access to information has an important place in the efficiency of education and training. In order to support the learning realized in the individual, there are changes in the means of access to the information transferred from outside. Students' attitudes towards mobile learning are important for the widespread use of mobile learning systems (Al-Emran, Elsherif and Shaalan, 2016). It is important to determine the attitudes of preservice teachers towards this new learning approach in order to use the new information transfer tools that come into our lives with smart mobile phones and tablets for the purpose of information transfer in the education and training environment. Researchers emphasize that determining attitudes of students and educators about mobile learning to determine whether they are ready to use mobile learning is an important issue that needs to be examined (Al-Emran, Elsherif and Shaalan, 2016). 
In this study, it was aimed to determine pre-service teachers' attitudes towards mobile learning. The following research questions have been developed to achieve the research objective:

1. Do the participants' attitudes towards mobile learning and attitude sub-factors (advantage, limitation, usability, freedom) differ according to gender?

2. Do the participants' attitudes towards mobile learning and the subfactors of attitude sub-factors (advantage, limitation, usability, freedom) differ according to their undergraduate programs?

3. Do the attitudes of the participants towards mobile learning and the sub-factors of attitude sub-factors (advantage, limitation, usability, freedom) differ according to the weekly internet access times on the mobile device?

In this study, descriptive research model was chosen to determine the attitudes of teacher candidates towards mobile learning. In the study, cross-sectional survey design (Cross-Sectional Survey Design) was used to collect one-time data (Creswell, 2002). The M-learning attitude scale developed by Çelik (2013) was prepared as an optical form in order to eliminate data entry errors. The M-learning attitude scale was prepared by the prospective teachers and the data was transferred to the computer by the optical reader. Thus, errors that may arise from data entry are minimized.

The population of the study consisted of prospective teachers studying at the Faculties of Education. The target population of the study consisted of pre-service teachers who were educated in the faculty of education of a state university in the Western Black Sea part of the Turkey. The study included 1004 prospective teachers. In the sample selection of the study, whole sampling method was used and for this purpose, all 2200 prospective teachers studying at the Faculty of Education were reached and asked to participate in the study on a voluntary basis. A total of 1104 pre-service teachers agreed to participate in the study by completing the attitude survey towards mobile learning. Of the 993 teacher candidates who participated in the study and stated their gender in the survey, $22.5 \%$ were male and $77.5 \%$ were female teacher candidates. 
Data related to the study were collected by M-learning attitude scale developed by Çelik (2013). The scale consists of 21 items. A five-point Likerttype scale was used for each item in the scale, which includes the options of Strongly Disagree, Disagree, Neatural, Agree, Strongly Agree. M-learning attitude scale consists of four factors. These factors are the advantages of M-Learning, limitations in M-Learning, usefulness in M-Learning and freedom in M-Learning. Cronbach Alpha internal consistency coefficient of the questionnaire was calculated as 0.881 by Çelik (2013). As a result of the analysis of the data collected in this study, the Cronbach Alpha value, which indicates the total reliability of the scale according to the internal consistency values expressed with Cronbach Alpha, was calculated as 0.885 .

The factors included in the scale were named as advantages of m-Learning, limitations in $\mathrm{m}$-Learning, usefulness in $\mathrm{m}$-Learning and freedom in $\mathrm{m}$-Learning, respectively. There were 5 negative items (under the limitation dimension) and 16 positive items in the scale items. According to the results of the confirmatory factor analysis (CFA), a good agreement was found between the data set and the factor structure of the scale.

In the analysis of the research questions, due to the high number of participants, t-test, ANOVA test, Tamhane's T2 and Bonferroni Post Hoc tests were used for samples independent of parametric tests. These tests were compared with the data of two and more groups.

In today's world where the use of mobile devices is widespread (BrizPonce et al., 2017; Oz, 2014), it is important to determine the attitudes of prospective teachers who will become teachers in the near future prior to the use of mobile devices for education purposes (Al-Emran, Elsherif and Shaalan, 2016). ). This study was carried out in order to determine the attitudes of prospective teachers about mobile learning. As a result of the study, it was determined that the attitudes of the prospective teachers towards mobile learning were generally positive. These findings indicate that students are willing to learn mobile. In addition, it was determined that the attitudes of the prospective teachers towards mobile learning did not differ according to gender. Similar results have been obtained in studies investigating attitudes towards mobile learning in different contexts (Al-Emran, Elsherif and Shaalan, 2016; Pruet, Ang and Farzin, 2016). The 
results of the studies show that pre-service teachers' attitudes towards mobile learning are positive without changing gender.

It has been determined that pre-service teachers' attitudes towards mobile learning change according to their teaching programs. According to this, it was determined that the attitudes of the teacher candidates studying in the Department of Teaching for the Mentally Handicapped on mobile learning were higher than the prospective teachers in the Mathematics and Turkish Language Teaching Departments. These results suggest that teachers of the Mentally Handicapped Department will tend to use mobile learning tools more in the future. From this point of view, it is understood that the preparation of the content that can be used with the mobile devices related to the prospective teachers studying in the Mentally Handicapped section should be started.

As a result of the study, it was determined that the attitudes of the prospective teachers towards mobile learning changed according to the weekly internet usage times of the prospective teachers. Accordingly, preservice teachers' attitudes towards mobile learning are higher than those with less internet usage times. The duration of use of mobile devices and the internet positively affects the attitude towards mobile learning (AlEmran, Elsherif and Shaalan, 2016; Tekerek, Altan \& Gündüz, 2014).

According to the results of the study, it was observed that mobile learning reduced the interaction in the classroom (Heflin, Shewmaker and Nguyen, 2017), that individuals were distracted in the use of mobile technologies for learning, and that individuals tended not to participate in learning activities. The results of the study suggest that skills are lower (Heflin, Shewmaker and Nguyen, 2017) and individuals have lower levels of course achievement (Martin and Ertzber-ger, 2013). Mobile learning usage preferences should be made by taking into consideration the returns that come with each innovation and the ratio of their losses.

\section{Suggestions}

In the planning of education and training activities, activities in which preservice teachers of the Mentally Handicapped department can use mobile technologies should be included. In addition, three quarters of the sample 
in which the data obtained in this study were collected is a sample of female teacher candidates. Although gender has not been identified as a factor affecting attitudes towards mobile learning, the sample should be repeated in future studies by choosing samples with a similar proportion of female and male prospective teachers. In addition, it is emphasized that social impact is an important factor for individuals to use mobile learning (Briz-Ponce, et al., 2017). In future studies, it should be investigated how teachers who actively use mobile learning affect other colleagues.

\section{Kaynakça / References}

Al-Emran, M., Elsherif, H. M., ve Shaalan, K. (2016). Investigating attitudes towards the use of mobile learning in higher education. Computers in Human Behavior, 56, 93-102.

Briz-Ponce, L., Pereira, A., Carvalho, L., Juanes-Méndez, J. A., ve GarcíaPeñalvo, F. J. (2017). Learning with mobile technologies-Students' behavior. Computers in Human Behavior, 72, 612-620.

Creswell, J. W. (2002). Educational research: Planning, conducting, and evaluating quantitative (pp. 146-166). Upper Saddle River, NJ: Prentice Hall.

Çelik, A. (2013). M-öğrenme tutum ölçeği: Geçerlik ve güvenirlik analizleri. Ĕ̆itim ve Öğretim Araştırmaları Dergisi, 2(4), 172-185.

Dikbaş, E. (2006). Öğretmen adaylarının e-öğrenmeye yönelik tutumlarının incelenmesi. Yayımlanmamış Doktora Tezi, DEÜ Eğitim Bilimleri Enstitüsü, İzmir.

Gunter, G. A., ve Reeves, J. L. (2017). Online professional development embedded with mobile learning: An examination of teachers' attitudes, engagement and dispositions. British Journal of Educational Technology, 48(6), 1305-1317.

Heflin, H., Shewmaker, J., ve Nguyen, J. (2017). Impact of mobile technology on student attitudes, engagement, and learning. Computers ve Education, 107, 91-99.

Hsieh, W. M., ve Tsai, C. C. (2017). Taiwanese high school teachers' conceptions of mobile learning. Computers ve Education, 115, 82-95.

Hu, L. T., ve Bentler, P. M. (1999). Cutoff criteria for fit indexes in covariance structure analysis: Conventional criteria versus new alternatives. Structural Equation Modeling, 6(1), 1-55. 
Hwang, G. J., ve Chang, H. F. (2011). A formative assessment-based mobile learning approach to improving the learning attitudes and achievements of students. Computers \&e Education, 56(4), 1023-1031.

Martin, F., ve Ertzberger, J. (2013). Here and now mobile learning: An experimental study on the use of mobile technology. Computers $\mathcal{E}$ Education, 68, 76-85.

$\mathrm{Oz}, \mathrm{H}$. (2014). Prospective English teachers' ownership and usage of mobile devices as m-learning tools. Procedia-Social and Behavioral Sciences, 141, 1031-1041.

Pruet, P., Ang, C. S., ve Farzin, D. (2016). Understanding tablet computer usage among primary school students in underdeveloped areas: Students' technology experience, learning styles and attitudes. Computers in Human Behavior, 55, 1131-1144.

Sánchez, A. B., Marcos, J. J. M., ve GuanLin, H. (2012). In service teachers' attitudes towards the use of ICT in the classroom. Procedia-Social and Behavioral Sciences, 46, 1358-1364.

Sharples, M., Arnedillo-Sánchez, I., Milrad, M., ve Vavoula, G. (2009). Mobile learning. In Technology-enhanced learning (pp. 233-249). Springer, Dordrecht.

Tekerek, M., Altan, T. ve Gündüz, İ. (2014). FATIH Projesinde Tablet PC Kullanımına Yönelik Öğrenci Tutumlarının İncelenmesi. Bilişim Teknolojileri Dergisi, 7(2), $21-27$.

\section{Kaynakça Bilgisi / Citation Information}

Turgut, K. ve Akdemir, E. (2019). Öğretmen adaylarının mobil öğrenmeye ilişkin tutumları. OPUS-Uluslararası Toplum Araştırmaları Dergisi, 13(19), 500-526. DOI: 10.26466/opus.595870. 